\title{
A SANS Study of the Self-Assembly in Solution of Syndiotactic Polypropylene Homopolymers, Syndiotactic Polypropylene-block-poly(ethylene-co-propylene) Diblock Copolymers, and an Alternating Atactic-I sotactic Multisegment Polypropylene
}

\section{Aurel Radulescu, ${ }^{, \dagger}$ Robert T. Mathers, ${ }^{\ddagger}$ Geoffrey W. Coates, ${ }^{\ddagger}$ Dieter Richter, ${ }^{\dagger}$ and Lewis J . Fetters $\$$}

Institute for Solid State Research, Research Center, J ülich GmbH, 52425 J ülich, Germany, Department of Chemistry and Chemical Biology, Cornel U University, Ithaca, New York 14853-1301, and School of Chemical and Biomolecular Engineering, Cornell University, Ithaca, New York 14853-5021

Received March 24, 2004; Revised Manuscript Received May 7, 2004

\begin{abstract}
We have studied by small-angle neutron scattering (SANS) the crystallization of syndiotactic polypropylene (SPP) homopolymer in dilute hydrocarbon solution in parallel with the self-assembling behavior of crystalline-amorphous block copolymers of (syndiotactic propylene)-block-poly(ethylene-copropylene) [sPP-P(E-co-P)] and atactic-isotactic multiblock polypropylene copolymers (aPP-iPP). Homopolymers and diblock copolymers of various molecular weights and volume fractions were investigated in decane over a wide temperature range (between 160 and $-20^{\circ} \mathrm{C}$ ) while the temperature evolution of the aPP-iPP aggregates was studied in dodecane starting from $175^{\circ} \mathrm{C}$. The homopolymer crystallizes by forming platel ets of a thickness of about $60-65 \AA$, independent of the molecular weight or polymer volume fraction in solution. The diblock copolymers aggregate by forming a complex morphol ogy that shows a multilevel structure. This was investigated with SANS and ultra-SANS (USANS) over 3 orders of magnitude in size scale. At small scale (tens of angstroms) an overall 2-dimensional structure seems to be formed. It evolves at intermediate scale (hundreds of angstroms) into a rodlike structure. The rods associate in bundles that at a micrometric scale form supramol ecular structures like networks. Such an association could be promoted by the PE sequences present within the $P(E-c o-P)$ block. The multiblock copolymer forms very open rodl ike aggregates and demonstrates that the general morphol ogy of self-assembling materials with multiple alternating crystalline-amorphous blocks appears to be 1-dimensional.
\end{abstract}

\section{Introduction}

The self-assembly of crystalline-amorphous poly(coolefins) in dilute solution has been shown via smallangle neutron scattering (SANS) to yield either platelike or needlelike aggregates. The resultant supramolecular structures are dependent upon the copolymer architecture. The crystalline-amorphous diblock copolymers yield self-assembled hairy plates ${ }^{1}$ while the corresponding random copolymers yield one-dimensional needleshaped aggregates. ${ }^{2}$ Such polymers have demonstrated that they can serve as potent "pour point" depressants in refined fuel $\mathrm{s}^{3,4}$ or high wax containing crude oils. ${ }^{5-7}$ The crystalline component in these diblock and random copolymer structures has been made of ethylene units produced by hydrogenation of polybutadiene chains with varying 1,2- and 1,4-microstructure. The polymers in question were prepared via anionic polymerization and subsequent hydrogenation. Those samples possessed near-monodisperse molecular weight distributions. The crystalline-amorphous diblocks are present in commercial formulations (Infinium, Ltd., Paraflow series) used as wax crystal modifiers in middle distillate fuels.

To date, this combination of chemistries has been the most common and useful route to model atactic poly(olefin) and poly(co-olefin) structures. A recent publication ${ }^{8}$ has announced that near-monodisperse

${ }^{\dagger}$ J ülich $\mathrm{GmbH}$

‡ Department of Chemistry and Chemical Biology, Cornell University.

$\S$ School of Chemical Engineering and Biomolecular Engineering, Cornell University. poly(co-ol efin) homopolymers and diblocks can be pre pared from ol efin monomers, allowing the synthesis in a direct fashion of polyolefin chains that are not possible via the two-step anionic/hydrogenati on routes. Crystalline-amorphous diblock copolymers of (syndiotactic propylene)-block-poly(ethylene-co-propylene) [sP P-(P(ECo-P)] and atactic-isotactic multiblock polypropylene copolymers (aPP-iPP) ${ }^{9}$ have been investigated by SANS in parallel with the syndiotactic polypropylene homopolymers (SPP) in order to gain initial insight about the self-assembling characteristics of these materials in dilute hydrocarbon solution.

\section{Experimental Section}

2.1. Samples. The syndiotactic polypropylene homopolymer, SPP, and the crystalline-amorphous diblock polymers, SPP$P(E-c o-P)$, were prepared via a living polymerization in toluene at $0{ }^{\circ} \mathrm{C}$ using a bis(salicylaldiminato)titanium complex. ${ }^{8} \mathrm{All}$ air- and moisture-sensitive chemistry was carried out in a Braun Labmaster drybox or using standard Schlenk line techniques. The solvents were dried on solvent columns containing molecular sieves, alumina, and activated copper. Propylene (Matheson, Polymer Grade) was purified by a column containing molecular sieves and alumina.. Ethylene (Matheson, Polymer Grade) was used as received. Methylaluminoxane (MAO-I P, 12.9 wt \% Al in toluene, Akzo Nobel) was dried under vacuum at $60{ }^{\circ} \mathrm{C}$ for $24 \mathrm{~h}$. The alternating aPP/iPP multisegment polypropylene was made with a hafnium tert-butyl catalyst with the structure [(2-(3,5-(t-Bu) ${ }_{2} \mathrm{Phl}$ nd $)_{2^{-}}$ $\left.\mathrm{HfCl}_{2}\right)$ ]. The pol ymerization was performed in liquid propylene under pressure at $50{ }^{\circ} \mathrm{C}$ using MAO with $[\mathrm{Al} / \mathrm{Hf}]=1000 .^{9}$

The polymer ${ }^{1} \mathrm{H}$ NMR spectra were recorded on a Varian Inova $500 \mathrm{MHz}$ spectrometer and referenced to nondeuterated 
Table 1. Polyolefin Molecular Characteristics and SANS Experimental Conditions

\begin{tabular}{|c|c|c|c|c|c|c|c|}
\hline sample & $\begin{array}{c}\mathrm{M}_{\mathrm{w}} \times 10^{-3} \\
\left(\mathrm{~g} \mathrm{~mol}^{-1}\right)\end{array}$ & $\mathrm{M}_{\mathrm{w}} / \mathrm{M}_{\mathrm{n}}^{\mathrm{a}}$ & $\begin{array}{l}\text { mole fraction } \\
\text { ethylene }\end{array}$ & $\mathrm{T}_{\mathrm{m}}\left({ }^{\circ} \mathrm{C}\right)^{\mathrm{c}}$ & $\mathrm{T}_{\mathrm{g}}\left({ }^{\circ} \mathrm{C}\right)^{\mathrm{C}}$ & $\left\langle\mathrm{R}_{\mathrm{g}}\right\rangle_{0}(\AA)$ & $\begin{array}{l}\text { instrumental } \\
\text { conditions }\end{array}$ \\
\hline SPP-1 & $43.4^{a}$ & 1.08 & & $\sim 148$ & $\sim 0$ & & $\mathrm{KWS} 2, \lambda=7 \AA$ \\
\hline SPP-2 & $61.4^{a}$ & 1.10 & & $\sim 148$ & $\sim 0$ & 104 & KWS2, $\lambda=7 \AA$ \\
\hline SPP-3 & $85.0^{a}$ & 1.11 & & $\sim 148$ & $\sim 0$ & & $\mathrm{KWS} 2, \lambda=7 \AA$ \\
\hline SPP-P(E-co-P)-1 & $\begin{array}{l}22.3^{e}-47.0^{f} \\
(65.1)^{d}\end{array}$ & $1.07^{\mathrm{e}}: 1.09^{\mathrm{f}}$ & $0.19: 0.26^{g}$ & $135^{\mathrm{h}}$ & $-34^{i}$ & 108 & $\begin{array}{l}\text { KWS2, } \lambda=7 \AA \\
\text { KWS2, } \lambda=12 \AA\end{array}$ \\
\hline sPP-P(E-co-P)-2 & $\begin{array}{l}38.4 \mathrm{e}-106.6^{f} \\
(138.9)^{\mathrm{d}}\end{array}$ & $1.11^{\mathrm{e}}: 1.12^{\mathrm{f}}$ & $0.25: 0.33 \mathrm{~g}$ & $131^{\mathrm{h}}$ & $-45^{i}$ & 146 & $\begin{array}{l}\text { KWS2, } \lambda=7 \AA \\
\text { KWS3, } \lambda=12 \AA\end{array}$ \\
\hline aPP-iPP & $107.0^{d}$ & $\sim 2$ & & & $\sim 0$ & 156 & $\mathrm{KWS} 2, \lambda=7 \AA$ \\
\hline
\end{tabular}

a Via SEC. ${ }^{b}$ Determined using ${ }^{13} C$ NMR. ${ }^{c}$ Measured by DSC. d Via SANS. e Via SEC for the SPP segment. ${ }^{f}$ Via SEC for the diblock $\mathrm{P}(\mathrm{E}-\mathrm{CO}-\mathrm{P})$ segment. $\mathrm{g}$ The first number denotes the ethylene mole fraction for the entire diblock copolymer while the second number is the ethylene mole fraction for the $\mathrm{P}(\mathrm{E}-\mathrm{CO}-\mathrm{P})$ segment. ${ }^{\mathrm{h}} \mathrm{SPP}$ block. ${ }^{\mathrm{i}} \mathrm{P}(\mathrm{E}-\mathrm{CO}-\mathrm{P})$ segment.

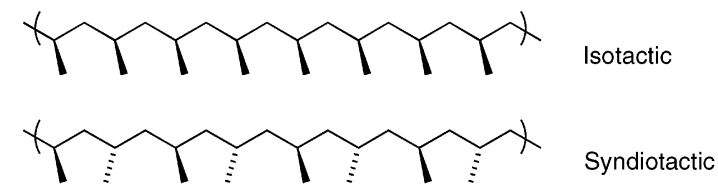

Figure 1. Stereochemical configurations of polypropylene.

solvent shifts. The preliminary molecular weights $\left(M_{n}\right.$ and $\left.M_{w}\right)$ and polydispersity indices $\left(M_{w} / M_{n}\right)$ were measured by a Waters Alliance GPCV 2000 size exclusion chromatograph (SEC). The SE C columns (four Waters HT 6E and one Waters HT 2) were eluted with 1,2,4-trichlorobenzene containing 0.01 wt $\%$ ditert-butylhydroxytoluene $(\mathrm{BHT})$ at $1.0 \mathrm{~mL} / \mathrm{min}$ at $140{ }^{\circ} \mathrm{C}$. DSC analysis was performed on a TA I nstruments Q1000 equipped with a liquid nitrogen cooling system and automated sampler. Typical DSC experiments were made in crimped aluminum pans under nitrogen with a heating rate of $10^{\circ} \mathrm{C} / \mathrm{min}$ from -50 to $+200{ }^{\circ} \mathrm{C}$. The reported DSC data from the second heating run were processed with the TA Q Series software. The $T_{g}$ values of the amorphous $P(E-C O-P)$ segments were around $-59^{\circ} \mathrm{C}$.

The sPP in the bulk crystalline state assumes a helical chain conformation containing alternating dimer "trans-gauche" conformers. Figure 1 shows the two stereochemical configurations of polypropylene. The morphology of SPP when formed by isothermal crystallization from the melt is that of radiating lamellae. ${ }^{10}$

Various polymeric materials based on SPP were investigated by SANS in dilute solution to determine the temperature evolution of their self-assembling behavior. A sPP homopolymer of a molecular weight of $M_{w}=61400 \mathrm{~g} \mathrm{~mol}^{-1}$ was investigated over a wide temperature range (between the single coil and the aggregation regime) in two polymer solutions $(0.5 \%$ and $1 \%$ polymer volume fractions). Additionally, SPP polymers of $M_{w}=43400$ and $85000 \mathrm{~g} \mathrm{~mol}^{-1}$ were also investigated in order to evaluate the dependence of the aggregation parameters on molecular weight. Two SPP - P(Eco-P) diblocks were also studied. The overall SEC molecular weights $\left(\mathrm{M}_{\mathrm{w}}\right)$ of these samples were 69300 and $145000 \mathrm{~g}$ $\mathrm{mol}^{-1}$, while those of the sPP blocks were 22300 and $38400 \mathrm{~g}$ $\mathrm{mol}^{-1}$, respectively. The $M_{w} / M_{n}$ ratios for these samples were $\sim 1.1$. F or the multisegment aPP-iPP polymer $M_{w} / M_{n}$ was $\sim 2$. The molecular characteristics of the polyol efins used in this work are given in Table 1 . The $\mathrm{M}_{\mathrm{w}}$ values were obtained from SEC and SANS at temperatures above the self-assembly event.

While both copolymers were investigated in a $0.5 \%$ pol ymer solution over a wide temperature range, the low molecular weight diblock was studied also at $-20^{\circ} \mathrm{C}$ in different solutions covering a very wide range of polymer concentrations $(0.05 \%$ and $20 \%$ ). Additionally, the self-assembling behavior of a multiblock (aPP-iPP) alternating copolymer was studied in dilute solution. It contained $\sim 50$ alternating aPP and iPP segments with a total sample molecular weight of ca. $10^{5} \mathrm{~g}$ $\mathrm{mol}^{-1}$. All polymer solutions were prepared in decane at 160 ${ }^{\circ} \mathrm{C}$, except that of the aPP-iPP multiblock copolymer. That was prepared in dodecane at $\sim 180{ }^{\circ} \mathrm{C}$ due to the $\sim 160{ }^{\circ} \mathrm{C}$ melting point of the iPP segments.
2.2. SANS Measurements. Since the melting point of the SPP is around $148{ }^{\circ} \mathrm{C}$, a very wide temperature range was investigated, between the single coil (at $160{ }^{\circ} \mathrm{C}$ ) and aggregation regime (below $40{ }^{\circ} \mathrm{C}$ ). For the multiblock material the upper limit of the temperature investigation was even higher $\left(175^{\circ} \mathrm{C}\right)$. Generally, the lowest limit of the measurement was established at $0{ }^{\circ} \mathrm{C}$ although the diblock copolymer solutions have been investigated to $-20^{\circ} \mathrm{C}$. The gap between the melting point and the self-assembly event in solution is quite large (more than $100{ }^{\circ} \mathrm{C}$ for some of the investigated polymers), particularly when compared to that of high-density polyethylene where the corresponding temperature gap is $\sim 30^{\circ} \mathrm{C}$. An additional point of distinction is that the SPP crystallites remain suspended in solution, and the samples do not show any sedimentation down to at least $-20^{\circ} \mathrm{C}$ while polyethylene precipitates from solution as soon as crystallization sets in (ca. $30{ }^{\circ} \mathrm{C}$ below the melting point). This failure of the SPP aggregates to precipitate appears to facilitate the preparation of the near-monodisperse mol ecular weight distributions from the living catalyst system. ${ }^{8}$

The majority of the SANS measurements were done at the KWSII instrument at the FRJ -2 research reactor (J ülich). The data were corrected for the scattering from empty cell and solvent and then calibrated in absolute units by using a Lupolen secondary standard ${ }^{11}$ according to

$$
\frac{\mathrm{d} \Sigma}{\mathrm{d} \Omega}=\frac{\mathrm{L}^{\mathrm{S}} \mathrm{h}^{\mathrm{S}} \mathrm{T}^{\mathrm{S}} \mathrm{MON}^{\mathrm{S}}(\mathrm{Q})}{\mathrm{LhTMONI}^{\mathrm{S}}(0)}\left(\frac{\mathrm{d} \Sigma(0)}{\mathrm{d} \Omega}\right)^{\mathrm{S}}
$$

Here S refers to the standard, MON denotes the total amount of monitor counts, $h$ is the sample thickness, $L$ is the sampleto-detector distance, and $T$ is the transmission. I(Q) is the scattered intensity, and $\mathrm{I}^{\mathrm{S}}(0)$ is the measured intensity of the standard at $\mathrm{Q}=0$. The value of $\mathrm{d} \Sigma(0) / \mathrm{d} \Omega$ for the Lupolen standard has been calibrated with vanadium to be 1.78155 $\mathrm{cm}^{-1}$.

The measurements were typically done by using a neutron wavelength of $7 \AA$ with three detector-to-sample distances. Hence, the $Q$ range between 0.002 and $0.14 \AA^{-1}$ was accessible. The SANS patterns taken at different detector positions were al ways fitted together. Thus, the measurements were done on solution of the same concentration. For some samples, whose structural features require a lower $\mathrm{Q}$ range (to $0.001 \AA^{-1}$ ), additional measurements were performed with a neutron wavel ength of $12 \AA$ (see Table 1). For the case of the higher molecular weight diblock copolymer (38.4K/106.6K) one measurement was done at the KWSIII ultra-SANS (USANS) instrument at room temperature to "increase" the Q range to $0.0001 \AA^{-1}$. This permitted access to the power law behavior characteristic of aggregate structures having large length scales. The principle of this instrument is based on a production of a one-to-one image of an entrance aperture on a detector by neutron reflection on a double-focusing ellipsoidal mirror. ${ }^{12}$ The entrance slit is placed in one focus of the mirror while the detector occupies the other. Combining the scattering patterns obtained at these two instruments, data were obtained on the multilevel morphology of aggregates formed by the SPP-P(E-co-P) copolymers in solution. Structures of size 
scales between 10 and $10000 \AA$ could be semiquantitatively resolved.

Working with fully protonated polymers the maximum contrast and the minimum incoherent background were achieved by choosing a fully deuterated solvent (d-22). In the case of the diblocks, the scattering length densities for the materials composing the samples were $\rho_{\text {spp }}=-0.33 \times 10^{10}$ $\mathrm{cm}^{-2}, \rho_{\text {PEP }}=-0.31 \times 10^{10} \mathrm{~cm}^{-2}$, and $\rho_{\mathrm{d} 22}=6.58 \times 10^{10} \mathrm{~cm}^{-2}$. Thus, both copolymer blocks are virtually matched with the only contrast occurring between them and the solvent.

2.3. Optical Microscopy. The SPP $(61.4 \mathrm{~K})$ and $S P P-P(E-$ co-P) $(38.4 \mathrm{~K}-106.6 \mathrm{~K})$ solutions in decane were examined by phase contrast microscopy with a Zeiss Axioplan 2 microscope. All observations were performed at room temperature after a prior heating of the samples to $160{ }^{\circ} \mathrm{C}$ followed by a slow cooling process spread over several hours. Micrographs of the structures and morphologies (formed by the crystallized or selfassembled materials) were captured by using a low light interacting camera.. The images presented here were obtained at different magnifications. The scale bars are shown in the microscopy figures.

\section{Theory}

At high temperatures, the polymers completely dissolve in the alkane solvent and thus yield scattering characteristics typical of single coils. Upon a decrease in temperature, the crystallization process results in the formation of large objects with a characteristic morpholog. The scattering from these objects is often characterized by a power law: ${ }^{13}$

$$
\mathrm{I}(\mathrm{Q}) \approx \mathrm{Q}^{-\alpha}
$$

where the exponent $\alpha$ reflects the spatial arrangements of the polymers. In the case of single coils, $\alpha=1 / v$, where the Flory exponent assumes $v=3 / 5$ for swollen and $v=$ $1 / 2$ for Gaussian chains. Beaucage has proposed a general form for the cross section of a fractal object combining both the Guinier regime and the fractal regime in a smooth way. ${ }^{14}$ For polymer chains it reads

$$
\frac{\mathrm{d} \Sigma}{\mathrm{d} \Omega}(\mathrm{Q})=\mathrm{G} \exp \left(-\mathrm{Q}^{2} \mathrm{R}_{\mathrm{g}}^{2} / 3\right)+\mathrm{B}\left\{\left[\operatorname{erf}\left(\mathrm{wQR}_{\mathrm{g}} / \sqrt{6}\right)\right]^{3} / \mathrm{Q}\right\}^{1 / v}
$$

with an $\mathrm{Q}^{-1 / v}$ asymptote, a crossover length $\sqrt{6} \mathrm{R}_{\mathrm{g}}$ (equal to the end-to-end distance of the chain), and $w$ $=1.06 . \mathrm{R}_{\mathrm{g}}$ thereby is the radius of gyration of the chain. The amplitudes $\mathrm{G}$ and $\mathrm{B}$ are related to each other: $\mathrm{B}=$ $\mathrm{G} v / \mathrm{R}^{1 / v} \Gamma(v)$ with $\Gamma$ (the Gamma function). $\mathrm{G}$ is the classical Guinier prefactor:

$$
\mathrm{G}=\Phi(1-\Phi) \mathrm{V}_{\mathrm{w}}\left(\rho_{\mathrm{p}}-\rho_{\mathrm{s}}\right)^{2}
$$

where $V_{w}$ is the chain volume.

The objects resulting from the aggregation process may assume different shapes like rods, platelets, fractal structures, and so on. The scattering from a rodlike structure is characterized by an exponent $\alpha=1$ in eq 2. Using the Guinier approximation, the cross section for such aggregates has the form

$$
\frac{\mathrm{d} \Sigma}{\mathrm{d} \Omega}(\mathrm{Q})=\Phi_{\text {rod }}\left(1-\Phi_{\text {rod }}\right) \pi \mathrm{F}_{\text {rod }} \Delta \rho_{\text {rod }}{ }^{2} \exp \left(-\mathrm{a}^{2} \mathrm{Q}^{2} / 4\right) / \mathrm{Q}
$$

where $F_{\text {rod }}=\pi \mathrm{a}^{2}$ is the perpendicular area of the rod, a is the rod radius, $\Phi_{\text {rod }}$ is the volume fraction of rods, and $\Delta \rho_{\text {rod }}$ is the contrast between the rod region and the solvent. The scattering of platelets with constant

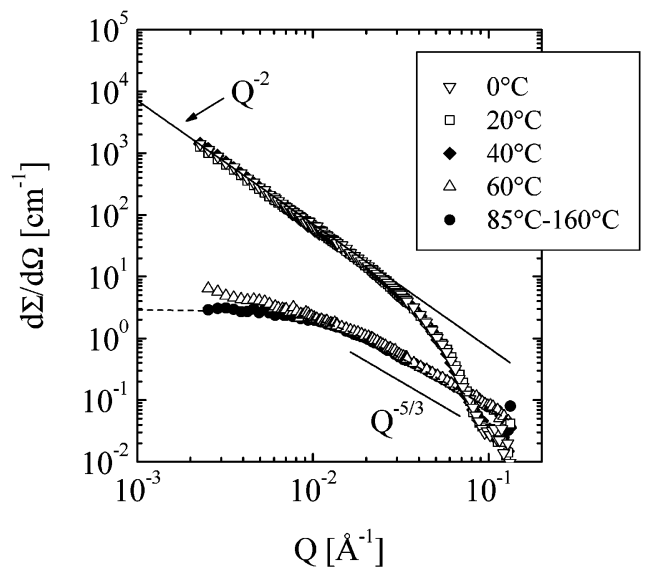

Figure 2. Scattering of SPP-2 in decane $\left(\Phi_{\mathrm{pol}}=0.5 \%\right)$ at different temperatures.

thickness leads to a $\mathrm{Q}^{-2}$ power law. Here, the Guinier approximation has the following form:

$\frac{\mathrm{d} \Sigma}{\mathrm{d} \Omega}(\mathrm{Q})=\Phi_{\mathrm{pt}}\left(1-\Phi_{\mathrm{pt}}\right) 2 \pi \mathrm{d} \Delta \rho_{\mathrm{pt}}{ }^{2} \exp \left(-\mathrm{d}^{2} \mathrm{Q}^{2} / 12\right) / \mathrm{Q}^{2}$

where $d$ is the plate thickness, $\Phi_{p t}$ is the volume fraction of the plates, and $\Delta \rho_{\mathrm{pt}}$ is the contrast between the plate region and the solvent. Aggregates representing 3-dimensional large objects with sharp interfaces and $\mathrm{QR}_{\mathrm{g}}$ $\gg 1$ give rise to Porod scattering:

$$
\frac{\mathrm{d} \Sigma}{\mathrm{d} \Omega}(\mathrm{Q})=\Phi_{\text {agg }} 2 \pi \Delta \rho^{2} \frac{\mathrm{S}_{\mathrm{v}}}{\mathrm{V}} \mathrm{Q}^{-4}=\mathrm{P}_{4} \mathrm{Q}^{-4}
$$

where $S_{V}$ is the surface, $V$ is the volume, and $\Phi_{\text {agg }}$ is the volume fraction of the aggregates. Exponents $\alpha<3$ and $3<\alpha<4$ in eq 2 relate to mass or surface fractals, respectively, while $\alpha>4$ is characteristic for diffuse interfaces.

It is known ${ }^{3,4,15}$ that block copolymers having $A-B$ crystalline-amorphous segments show a domain morphology consisting of alternating crystalline and amorphous regions. Thus, for such systems in the aggregation regime the scattering intensity may be described in terms of partial structure factors $\mathrm{P}_{\mathrm{ij}}(\mathrm{Q})$ according to

$$
\begin{array}{r}
\mathrm{I}(\mathrm{Q})=\left(\rho_{\mathrm{A}}-\rho_{\mathrm{S}}\right)^{2} \mathrm{P}_{\mathrm{AA}}(\mathrm{Q})+2\left(\rho_{\mathrm{A}}-\rho_{\mathrm{S}}\right)\left(\rho_{\mathrm{B}}-\rho_{\mathrm{S}}\right) \mathrm{P}_{\mathrm{AB}}(\mathrm{Q})+ \\
\left(\rho_{\mathrm{B}}-\rho_{\mathrm{S}}\right)^{2} \mathrm{P}_{\mathrm{BB}}(\mathrm{Q})(8)
\end{array}
$$

When both $\mathrm{A}$ and $\mathrm{B}$ blocks are visible, then the measured scattering patterns provide only information about the conformation of the copolymer as a whole while the particular structure of each block cannot be resolved. For such a purpose partially deuterated copolymers are needed to match one block with the solvent and to keep the other one visible.

\section{Results and Discussion}

4.1. SPP Homopolymers. Figure 2 displays scattering profiles measured at different temperatures from the $0.5 \%$ solution of SPP-2 in $\mathrm{d}-22$. The power law exponent specific for the characteristic structures formed by the polymer is also indicated. At $160^{\circ} \mathrm{C}$ all polymers are dissolved as single coils. The single-chain regime extends over a wide temperature range. The sPP homopolymers show a weak tendency to self-assemble at around $60{ }^{\circ} \mathrm{C}$. However, the process is prominently developed below this temperature. At $40{ }^{\circ} \mathrm{C}$ the scat- 

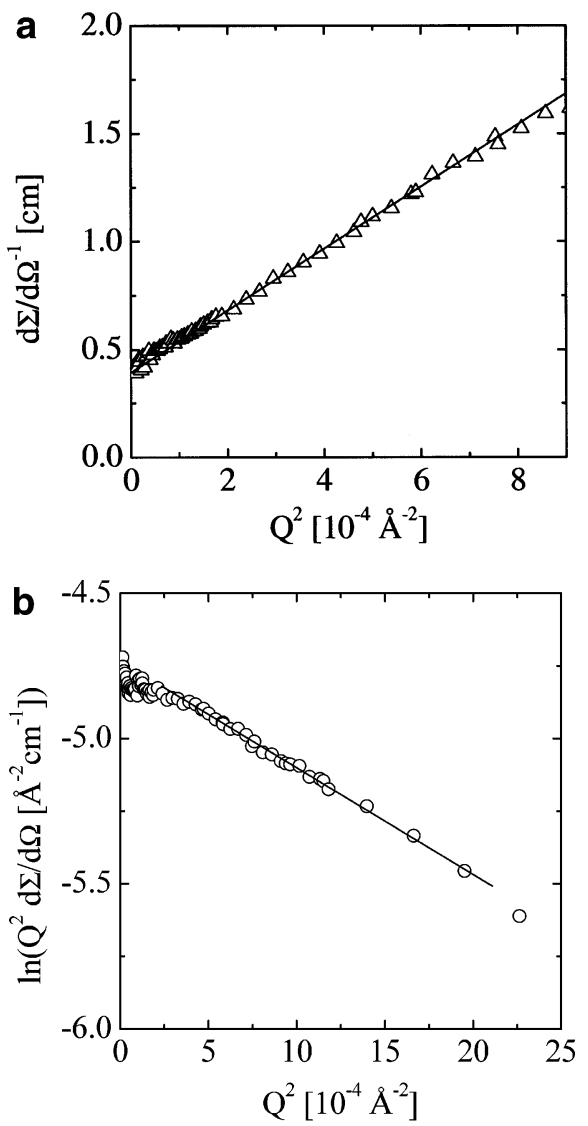

Figure 3. (a) Zimm plot of the scattering from single coils for the SPP-2 homopolymer. (b) 2-d Guinier plot of SPP data at $0{ }^{\circ} \mathrm{C}$ providing the parameters of the platelet-like aggregates.

tering intensity shows an increase of more than 3 orders of magnitude.

The analysis of the single-chain properties from the data has been performed in terms of the Zimm approximation

$$
\left[\frac{\mathrm{d} \Sigma}{\mathrm{d} \Omega}(\mathrm{Q})\left(\mathrm{N}_{\mathrm{A}} / \Delta \rho^{2}\right)\right]^{-1}=\frac{1}{\mathrm{~V}_{\mathrm{w}} \Phi}+\mathrm{LQ}^{2}
$$

with $\mathrm{L}=\mathrm{R}_{\mathrm{g}}{ }^{2} /\left(3 \Phi \mathrm{V}_{\mathrm{w}}\right)$. In plotting the inverse cross section vs $Q^{2}$, the slope $L$ and the forward scattering can be obtained (Figure 3a). Results of this analysis and those expected from the molecular characteristics of the polymers are in a good agreement. The chain dimension, in terms of the radius of gyration, of the SPP was found to be $104 \AA$. This is in good agreement with that of 101 $\AA$ calculated via the melt state based expression from J ones et al. ${ }^{16}$ Using the parameters obtained, the evaluated volume fraction of material in solution is $0.48 \%$. An overall fit with the Beaucage form factor (eq 3 ) was successful as one can see in Figure 2, where the dashed line represents the theoretical description of the experimental cross sections using the parameters from the Zimm analysis and an exponent $-5 / 3$ indicative for swollen single chains.

A decrease in the temperature promotes the formation of larger scale objects. The morphology of these objects can be easily identified from the clear $\mathrm{Q}^{-2}$ behavior of the intensity, characteristic for the scattering from platelets. Here, one can observe that the scattering patterns practically coincide for all temperatures bel ow

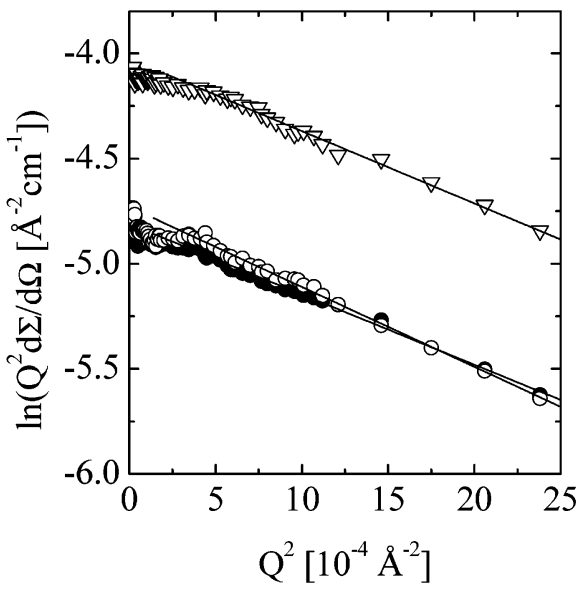

Figure 4. 2-d Guinier plot of data collected for different SPP homopolymers: (๑) $\mathrm{M}_{\mathrm{w}}=43.4 \mathrm{~K}, \Phi_{\mathrm{pol}}=0.5 \%$; (O) $\mathrm{M}_{\mathrm{w}}=85 \mathrm{~K}$, $\Phi_{\mathrm{pol}}=0.5 \% ;(\nabla) \mathrm{M}_{\mathrm{w}}=61.4 \mathrm{~K}, \Phi_{\mathrm{pol}}=1 \%$.

$40^{\circ} \mathrm{C}$. This shows that al most all polymers are involved in a rapid crystallization event once it starts. Since at low $\mathrm{Q}$ no deviation from the $\mathrm{Q}^{-2}$ slope was observed (a so-called Guinier regime), we may conclude that very large platelets (of sizes much larger than $1000 \AA$ ) are formed. The forward scattering $\mathrm{Q}^{2} \mathrm{~d} \Sigma(0) / \mathrm{d} \Omega=0.0084$ $\mathrm{cm}^{-1} \AA^{-2}$ and the thickness $\mathrm{d}=62 \AA$ of platel ets have been evaluated using eq 6 . Figure $3 b$ displays the respective 2-d Guinier plot. Using the obtained forward scattering and thickness and supposing compact platelets $\left(\Delta \rho_{\mathrm{pt}} \cong \Delta \rho_{\mathrm{pol}}\right.$ in eq 6$)$, the total volume fraction of polymers inside the platelets is evaluated to $0.46 \%$, which is very close to the value obtained from the single chain Zimm analysis (0.48\%).

A similar analysis of the aggregates formed in the case of different polymer volume fractions or molecular weights has shown that the compact polymers platelets always exhibit the same thickness of about $60-65 \AA$ (Figure 4). The questions arising are the following: (i) Why, with decreasing the temperature, do the SPP crystals not grow in the third direction? For comparison, in PE such aggregates quickly form large compact crystals which give rise to a Porod-like scattering within the $Q$ range typically accessible by SANS. (ii) Why is al most al ways the same thickness obtained for platelets formed from solutions of different polymer concentration or molecular weight?

We try to rationalize both observations by resorting to structural and thermodynamic literature data. The answers may be, to a certain extent at least, connected to each other. The early work of Marchetti and Martuscelli ${ }^{17}$ on solution-grown SPP single crystals in various solvents is apparently the initial effort in this field. They found narrow and elongated single crystals, with ill-defined end facets and with no evidence of any form of pyramidal structure. The low-angle X-ray diffraction revealed very thin lamellae grown at $0{ }^{\circ} \mathrm{C}$ from heptane with a thickness of about $65-70 \AA$, a value in good agreement with our results. Because of the poor syndiospecificity of the earlier vanadium-based catalysts, ${ }^{18}$ the materials investigated contained large amounts of iPP admixtures.

More recently, a large number of studies were dedicated to the investigation of the structure and morphology of sPP crystals grown from the melt for both poorly ${ }^{19}$ or highly 20,21 syndiotactic material. These studies re vealed rectangular crystals extending to many microme ters in lateral dimensions. The unit cell is orthorhombic 
with $a=14.5 \AA, b=11.2 \AA$, and $c=7.4 \AA$, and for the stable, high-temperature grown crystals (around 130 ${ }^{\circ} \mathrm{C}$ ), the chains are fully antichirally packed al ong both the $a$ and $b$ axes (strict alternation of right- and lefthanded helices). In decreasing the crystallization temperature, a structural disorder becomes more prominent. This produces a shift of SPP layers and errors in the alternation of helical hands in the bc plane and thus a progressive incorporation of isochiral packing defects. ${ }^{20,21}$ Lamellae of a thickness between 60 and 200 A showing a smooth and regular faceting are obtained with preferred growth along the crystal lographic b-axis. The SPP Iamellae are made by chain folding and show amorphous surfaces containing loops and folds. The preferential growth direction is along the crystallographic b-axis with loops at the lamella face preferentially pointing in the same direction. Possibly this preferred growth together with the evolving loop structure prevents growth into the third dimension and may explain the formation of extended isolated platelets from dilute solutions and the lack of sedimentation observed in our samples. On the other hand, despite the wellknown structural features of the SPP crystals grown from melt, the tendency of different $M_{w}$ SPP polymers to form in solution lamellae of the same thickness are not yet understood. A study of the chain folding behavior and the thermodynamics and kinetics of platelet formation may answer this question.

Figure 5 shows micrographs collected at room temperature from a solution of $0.5 \%$ SPP- 2 polymer in decane. Open structure aggregates with sizes between 5 and $15 \mu \mathrm{m}$ made by radially disposed smaller entities can be observed. The spherulitic morphology is formed by the radiating lamellae as reported for the typical crystallization from the melt. ${ }^{10}$ In this case the polymeric platel ets remain well-defined at smaller scale but associate in larger open structures which may give rise to an increase of the scattering intensity at much lower Q. From the SANS results we may conclude that the average distance between plates needs to be larger than $\mathrm{d}_{\min }=2 \pi / \mathrm{Q}_{\min } \cong 3000 \AA$. Though the size scales are much larger than those of the platelets identified by SANS, these aggregates support the notion of platelet association and confirm the absence of polymer growth into massive $3 d$ crystals characteristic of polyethylene.

4.2. SPP-P(E-co-P) Diblock Copolymers. The scattering profiles measured at different temperatures from the $0.5 \%$ polymer solution SPP-P(E-CO-P)-1 are displayed in Figure 6a. The power law exponents specific for different characteristic structures are indicated. At $160^{\circ} \mathrm{C}$ all polymers are dissolved as single coils, and this regime extends over a very wide temperature range, until somewhere bel ow room temperature. The Zimm analysis of the single-chain properties provides a value of $108 \AA$ for the radius of gyration $R_{g}$. The forward scattering yiel ds the diblock molecular weight of $65.1 \times 10^{3} \mathrm{~g} \mathrm{~mol}^{-1}$, in good agreement with that from SEC (see Table 1).

Within the aggregation regime the scattering patterns indicate a complex morphology of the self-assembled objects exhibiting a multilevel structure (at least two levels). At intermediate $\mathrm{Q}$ the power law behavior of $\mathrm{Q}^{-2}$ was tentatively identified. The power law may relate to a platelet-like substructure of the larger aggregates. However, because of the narrow $Q$ range over which the -2 gradient holds and because of the superposition of different signals in this $\mathrm{Q}$ range, the interpretation is
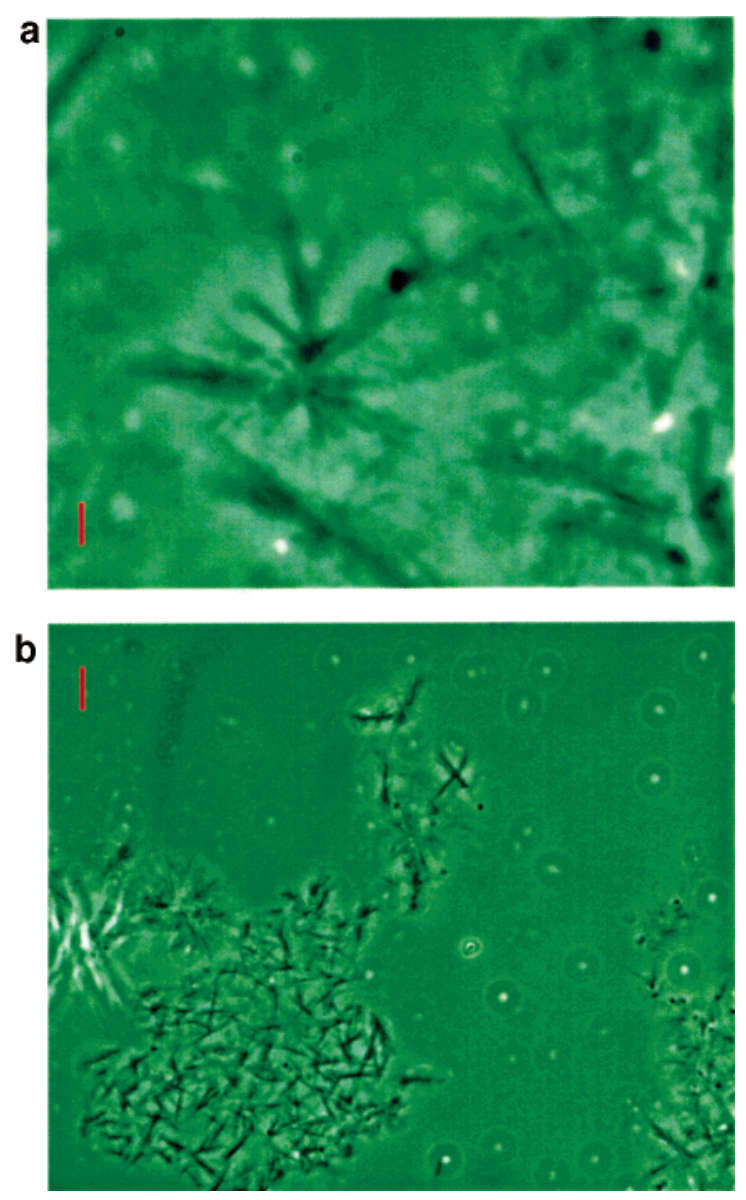

Figure 5. Micrographs of $0.5 \%$ solution of SPP- 2 in decane (room temperature). The scale bar represents $2 \mu \mathrm{m}$ (a) and $10 \mu \mathrm{m}$ (b).

still at a level of a supposition, and a Guinier analysis in terms of eq 6 would provide a suspect result. As one can see in eq 8 , when both A and B components (or blocks) are visible, the scattering intensity is a result of all three terms from the right-hand section. Since the s-PP block self-assembles in decane, while $P(E-c o-P)$ does not, different form factors and hence different architectures are seemingly involved. For a clear identification of the PP and P(E-Co-P) distribution within the aggregates partially deuterated diblocks are needed.

At low $\mathrm{Q}$ the power law $\left(\mathrm{Q}^{-1}\right)$ indicates larger objects with a rodlike shape. Since the power-law regime extends to the lowest Q values, their size cannot be evaluated. The intensity drop at higher $\mathrm{Q}$ is too sharp to be explained by a rod form factor. Therefore, we may assumethe presence of some extra intensity due to weak correlations between the aggregates. The lateral dimension of the rodlike aggregates, which in this case is buried by the correlation effect, may be accessed from measurements of solutions with much smaller polymer concentrations. Also, the evolution of the correlation peak may be followed by studying higher polymer concentrations. Figure $6 \mathrm{~b}$ presents a summary of the scattering patterns collected at $-20{ }^{\circ} \mathrm{C}$ for different polymer volume fractions. Combining measurements with neutron wavelengths of 7 and $12 \AA$ enlarged the available $Q$ range. At the lowest polymer concentration $\left(\Phi_{\mathrm{pol}}=0.1 \%\right)$ the 1-d characteristics and the rod-Guinier regime are clearly reveal ed while the peak evolution is easily observed for the higher polymer contents $\left(\Phi_{\text {pol }} \geq\right.$ $1 \%)$. Analyzing the lowest $\Phi_{\text {pol }}$ data in terms of the 1-d 

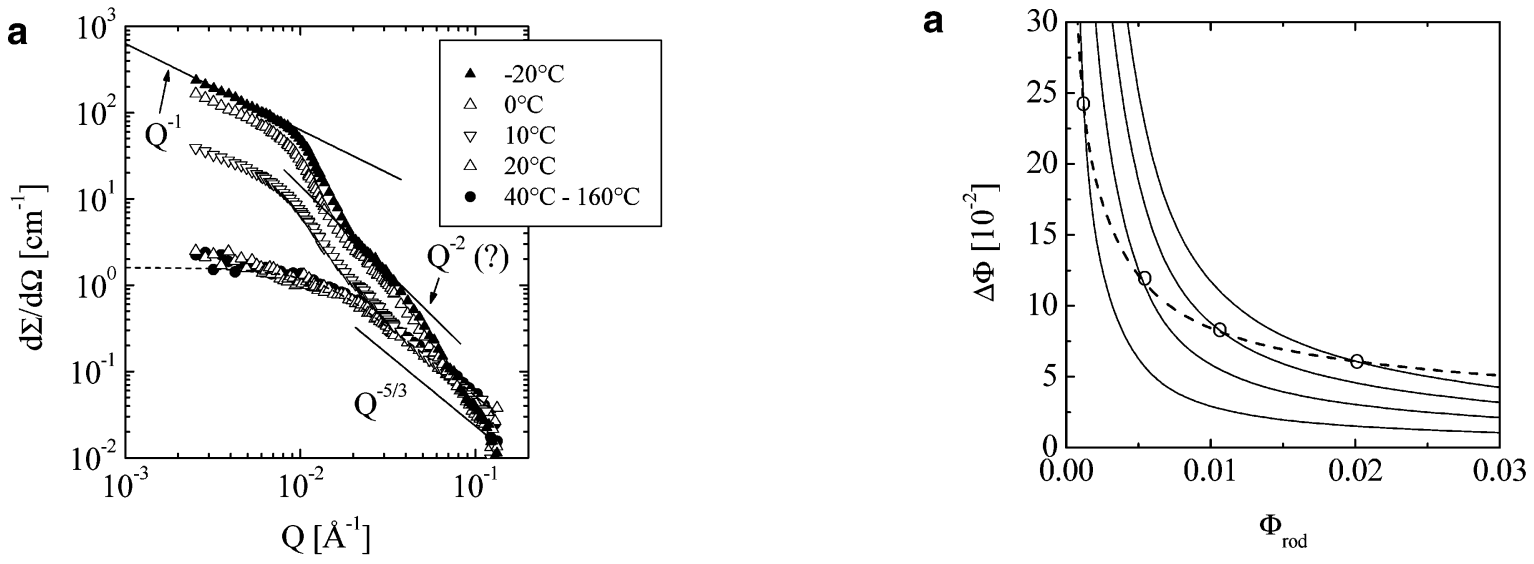

b

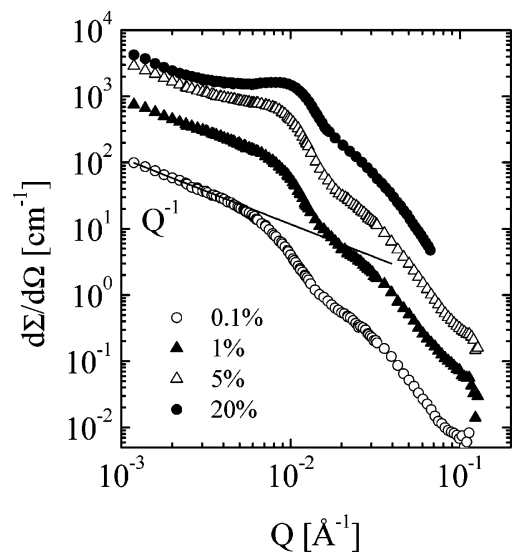

Figure 6. Scattering of SPP-P(E-co-P-1) in decane at different temperatures for $\Phi_{\text {pol }}=0.5 \%$ (a) and at $-20^{\circ} \mathrm{C}$ for different copol ymer volume fractions (b).

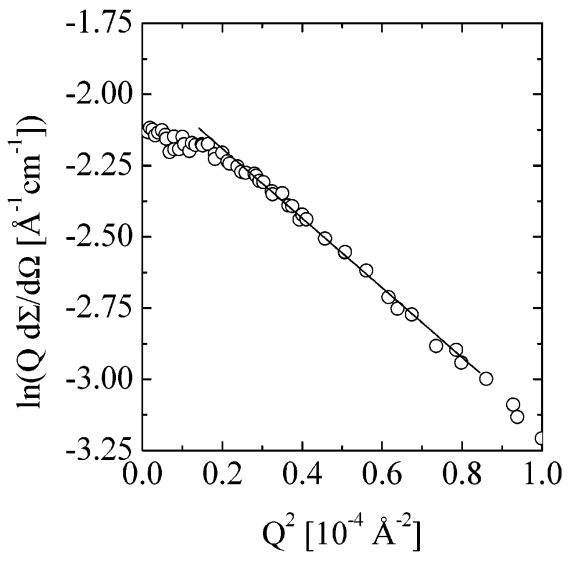

Figure 7. 1-d Guinier plot of SPP-P(E-Co-P)-1 data at $-20{ }^{\circ} \mathrm{C}$ providing the parameters of the rodlike aggregates.

Guinier approximation (eq 6), a rod radius $a=220 \AA$ and a forward scattering $\mathrm{Qd} \Sigma(0) / \mathrm{d} \Omega=0.14 \mathrm{~cm}^{-1} \AA^{-1}$ were evaluated (Figure 7).

To obtain information about the polymer density inside the rods, the forward scattering may be interpreted in a similar way as it was done in the case of $1-d$ aggregates formed by the PEB-11 random copolymer in decane. ${ }^{2}$ We note that since no independent information on the polymer volume fractions within the rod and in the remaining solution is available, only functional relations may be given. We, thus, have to distinguish between polymers in the aggregates and those remaining in solution:

$$
\Phi_{\mathrm{pol}}=\Phi_{\mathrm{pol}}^{\mathrm{agg}} \Phi_{\mathrm{rod}}+\Phi_{\mathrm{pol}}^{\mathrm{sol}}\left(1-\Phi_{\mathrm{rod}}\right)
$$

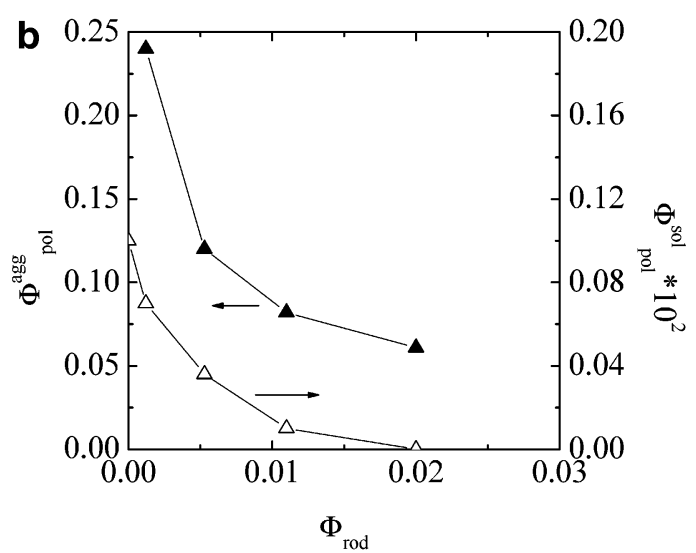

Figure 8. (a) Difference between the aggregated and free polymer volume fraction $\Delta \Phi$ as a function of rods volume fraction $\Phi_{\text {rod. }}$. The dashed line gives the result based upon the experimental forward scattering (eq 12). The solid lines represent $\Delta \Phi$ according to eq 11 for several hypothetical $\Phi_{\text {pol }}^{\text {sol }}$ (from above 0, 0.0025, 0.005, and 0.0075). The open circles directly relate $\Delta \Phi$ and $\Phi_{\text {rod }}$ to each other. (b) Aggregated volume fraction $\Phi_{\mathrm{pol}}^{\mathrm{agg}}$ and solved volume fraction $\Phi_{\mathrm{pol}}^{\mathrm{sol}}$ for the SPP-P(E-Co-P)-1 copolymer as a function of the rods fraction $\Phi_{\text {rod }}$ as they were obtained from the evaluation of the $\Delta \Phi$ (open circles in (a)) according to eq 11.

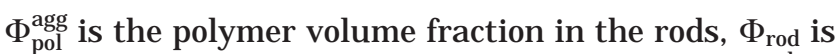
the volume fraction occupied by the rods, and $\Phi_{\text {pol }}^{\text {sol }}$ is the volume fraction in the rod-free solution. According to eq 5, the forward scattering from aggregates is proportional to the perpendicular area of the aggregates $F_{\text {rod }}$ and the contrast between the rod region and the solvent $\left(\Delta \rho_{\text {rod }}\right)^{2}$. The latter is a product between $\Delta \rho_{\text {pol }}$, the polymer contrast known from the molecular constituti on, and $\Delta \Phi$, the difference between the aggregated and free polymer volume fractions:

$$
\Delta \Phi=\left(\Phi_{\text {pol }}^{\mathrm{agg}}-\Phi_{\mathrm{pol}}^{\mathrm{sol}}\right)=\left(\Phi_{\text {pol }}-\Phi_{\text {pol }}^{\mathrm{sol}}\right) / \Phi_{\text {rod }}
$$

Since both copolymer blocks exhibit the same solvent contrast, a rearrangement of eq 5 gives

$$
\left.\Delta \Phi=\left\{\sqrt{\mathrm{Q} \frac{\mathrm{d} \Sigma}{\mathrm{d} \Omega}(0) /\left(\pi \mathrm{F}_{\mathrm{rod}} \Delta \rho_{\mathrm{pol}}{ }^{2}\right.}\right)\right\} /\left\{\sqrt{\Phi_{\mathrm{rod}}\left(1-\Phi_{\mathrm{rod}}\right)}\right\}
$$

This is plotted in Figure 8a as a function of the aggregated fraction $\Phi_{\text {rod }}$ together with $\Delta \Phi$ obtained for different $\Phi_{\text {pol }}^{\text {sol from eq } 11 .}$

Figure $8 \mathrm{~b}$ shows the dependence of the polymer volume fractions in solution and in the rod structures, following from eqs 11 and 12. Depending on the rod 


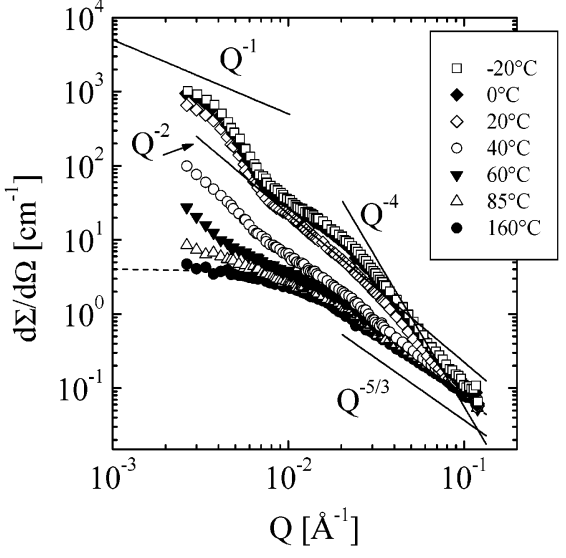

Figure 9. Scattering of $\mathrm{sPP}-\mathrm{P}(\mathrm{E}-\mathrm{co}-\mathrm{P})-2$ in decane $\left(\Phi_{\mathrm{pol}}=\right.$ $0.5 \%)$ at different temperatures.

volume fraction, the polymer density within rods is very low. The maximum possible volume fraction of rods is a little higher than $2 \%$-in this case all polymers would be concentrated within the rods $\left(\Phi_{\mathrm{pol}}^{\mathrm{sol}}=0\right)$ and $\Phi_{\mathrm{pol}}^{\mathrm{rod}} \cong$ $7 \%$. The smallest rod volume fraction leads to a maximum polymer content of around $25 \%$. These results show that the polymer rods are open objects. This conclusion is reasonable if we consider that the rods must be composed of compact SPP and swollen P(E-coP) sequences.

From the analysis of the peak evolution in Figure 6 one can observe that its position changes only slightly with the pronounced increase (1-20\%) of the polymer concentration. For monodisperse homogeneously distributed particle $\mathrm{Q}_{\max } \sim \Phi^{1 / 3}$ or $\Phi^{1 / 2}$ in the case of spherical ${ }^{23,24}$ or rodlike ${ }^{25-27}$ objects. The observed behavior does not fulfill any of these scaling relations. It may relate to a nonuniform density of rodlike objects in solution possibly due to a macroaggregation in clusters or bundles.

Figure 9 displays the scattering profiles measured at different temperatures from the $0.5 \%$ polymer solution of the higher molecular weight SPP-P(E-co-P-2) sample. The patterns look quite similar to those from the lower $M_{w}$ copolymer with the only difference that the structural features are shifted in temperature and $\mathrm{Q}$ range. Thus, for the higher $M_{w}$ copolymer the single-chain regime was found only at high $T$. The self-assembling event commences below $85^{\circ} \mathrm{C}$. A Zimm analysis of the single-chain profile at $160{ }^{\circ} \mathrm{C}$ provided a radius of gyration $R_{g}=146 \AA$ and a molecular weight of $139 \mathrm{~kg} /$ mol, again in good agreement with the SEC value (see Table 1). The SANS results taken within the aggregation regime reveal structural features at much lower $Q$ than for the low- $M_{w}$ sample. Also, the size scales for the aggregates are significantly larger. The $\mathrm{Q}^{-1}$ power law that is easily revealed in the previous case at low $Q$ is only hinted, while, at least for $\mathrm{T}=20^{\circ} \mathrm{C}$, the $\mathrm{Q}^{-2}$ power law extends over a wide intermediate $\mathrm{Q}$ range.

To better reveal the specific features of the large-scale aggregates and to identify clearly the specific power laws by using incident neutrons of $\lambda=12 \AA$, we extended the $\mathrm{Q}$ range down to $1 \times 10^{-3} \AA^{-1}$ (Figure 11 ). Scattering cross sections collected at $0{ }^{\circ} \mathrm{C}$ for two copolymer volume fractions $(0.5 \%$ and $0.1 \%)$ at low Q clearly revealed a $\mathrm{Q}^{-1}$ behavior and thus the presence of rods. In this case the perpendicular dimension of the rod could not be accessed even for a polymer concentration as low as $0.1 \%$. It seems that weak correlation

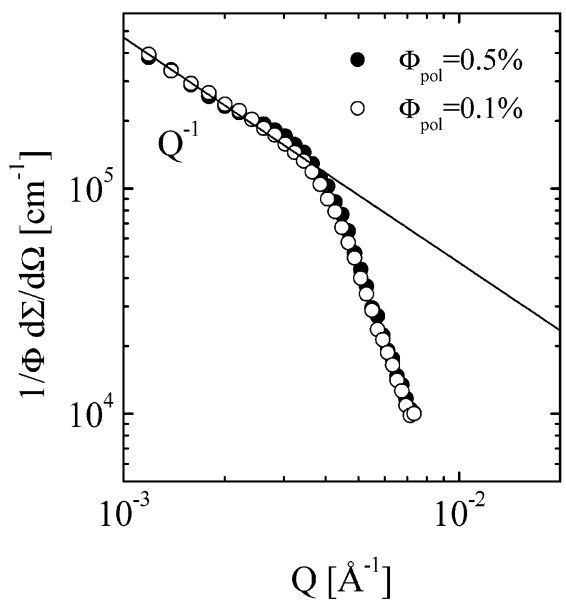

Figure 10. Scattering cross sections from $s P P-P(E-c o-P)-2$ diblock copolymer in $\mathrm{d}-22$ for two polymer volume fractions at $0{ }^{\circ} \mathrm{C}$.

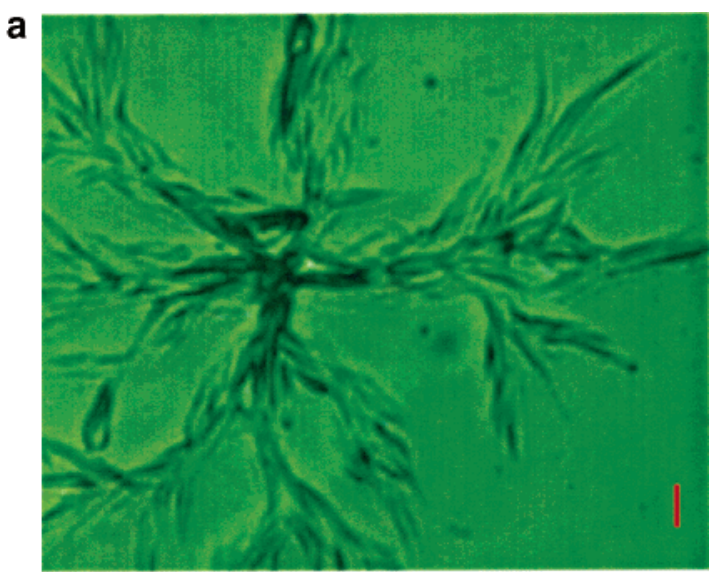

b

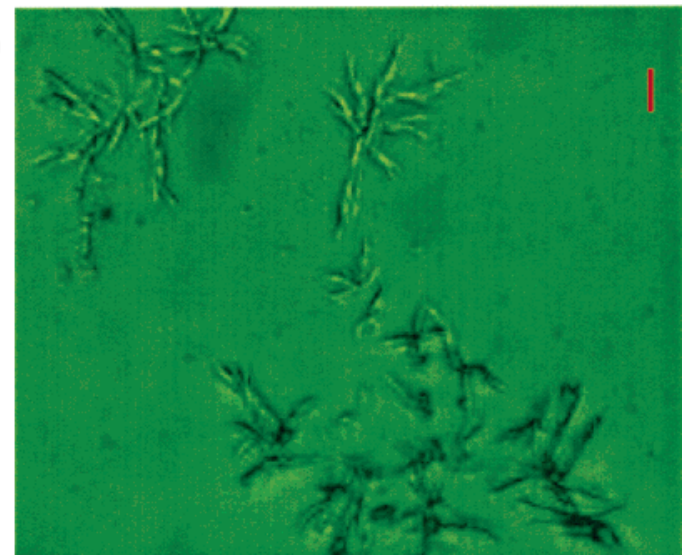

Figure 11. Micrographs of $0.5 \%$ solution of $s P P-P(E-C o-P)-2$ in decane. The scale bar represents $2 \mu \mathrm{m}$ (a) and $20 \mu \mathrm{m}$ (b).

effects are present just within the Q range where the Guinier regime is reached and give raise to a "shoulder"like structure at around $Q^{*} \cong(3.5-5) \times 10^{-3} \AA^{-1}$. This value corresponds to a correlation distance $\left(2 \pi / \mathrm{Q}^{*}\right)$ of about 1500-1800 $\AA$. Although the shoulder buries the form factor effect of the rod's lateral size, we estimate from the deviation from $\mathrm{Q}^{-1}$ behavior a rod radius of about $400 \AA$.

The values obtained for the lateral size of the polymeric rods scale well with the polymers' molecular characteristics. From the study of various $M_{w}$ PE-PEP diblocks in decane it was demonstrated ${ }^{1}$ that brush length scales with the monomer number $\mathrm{N}_{\text {PEP }}$ of the 


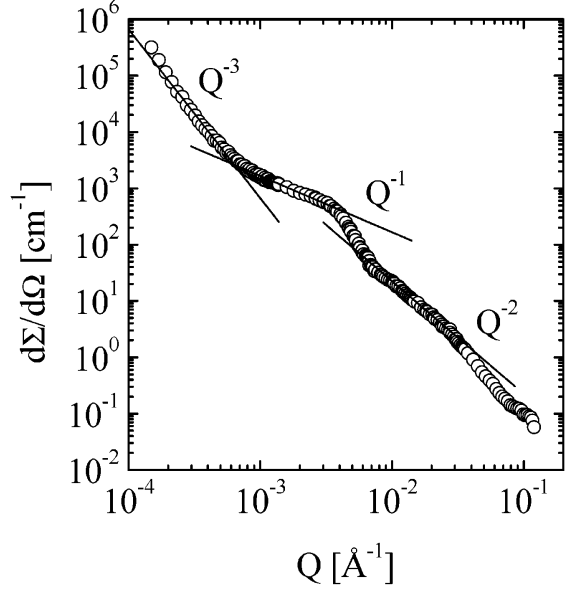

Figure 12. Scattering pattern from the $S P P-P(E-c o-P)-2$ at $20{ }^{\circ} \mathrm{C}$ measured over a wide $\mathrm{Q}$ range by combining the results from the pinhole USANS and the optical focusing SANS (see text).

corresponding block as $L_{b} \approx N_{P E P} 9 / 11$. The SPP-P(E-CO$\mathrm{P})$ diblocks are made from an SPP crystalline core and an amorphous $\mathrm{P}(\mathrm{E}-\mathrm{CO}-\mathrm{P})$ brush. The molecular weights of the two $\mathrm{P}(\mathrm{E}-\mathrm{Co}-\mathrm{P})$ blocks scale as $107 / 47=2.28$ (see Table 1 ) while the radii of the corresponding rods ( $a_{\text {small }}$ $=220 \AA, a_{\text {large }} \approx 400 \AA$ ) lead to a relation of the brush sizes of $(400-30) /(200-30) \cong 1.95(30 \AA$ is half the size of the SPP core), in reasonable agreement with the above scaling relation.

From the micrographs collected at room temperature from the $0.5 \%$ solution of high- $\mathrm{M}_{\mathrm{w}}$ diblock (Figure $11 a, b)$, the overall morphology and dimensions of the copolymer macroaggregates could be eval uated. Clearly visible bundles of the big 1-d aggregates associate by forming micron-scale objects that further form a ramified network-like morphology extending over tens of microns. A rough evaluation of the smallest elemental unit perceptible in Figure 1la gives for its perpendicular radius a value larger than $2000 \AA$. These 1-d-shaped objects are too "thick" to be observed by classical SANS; therefore, we estimate that they must represent smaller bundles formed by the rods we identified above by SANS.

The microscopy and classical SANS results are supported and completed by the additional measurements performed at the KWSIII optical focusing USANS instrument. There, in pinhole geometry, the $\mathrm{Q}$ range could be extended to $Q_{\min }=10^{-4} \AA^{-1}$. Figure 12 displays the scattering pattern from a $0.5 \%$ solution of SPP $-\mathrm{P}(\mathrm{E}-$ Co-P) -2 at $20^{\circ} \mathrm{C}$ over the whole $\mathrm{Q}$ range accessed in this study. This result nicely shows the multilevel structure of the copolymer aggregates and is consistent with the morphology revealed by the micrographs. By the aggregating SPP and amorphous P(E-Co-P) blocks at small scale a 2-d structure seems to be formed $\left(Q^{-2}\right.$ power law at larger Q). This structure evolves at intermediate scale into a rodlike structure $\left(Q^{-1}\right.$ power law at intermediate Q).

The rods associate in bundles and the correlation effects between them result in the "shoulder"-like structure at around $\mathrm{Q}^{*} \cong(3.5-5) \times 10^{-3} \AA^{-1}$. The correlation distance of about $1500-1800 \AA$ indicates that these bundles are fluffy aggregates. At much larger scale (micrometer order) the rod bundles form a networklike structure with mass fractal aspects $\left(Q^{-3}\right.$ power law at smaller Q). We may add that by a visual examination

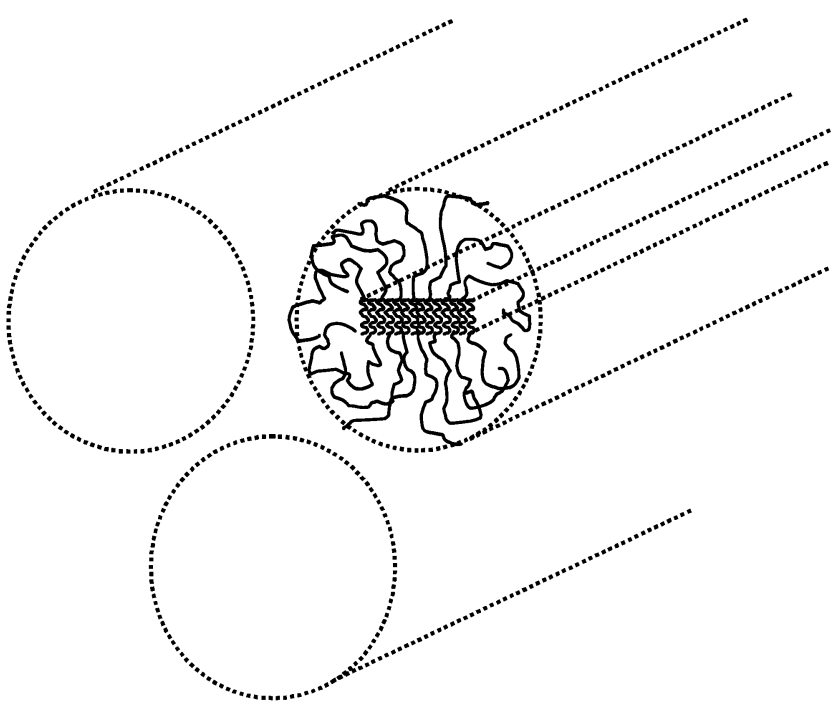

Figure 13. Schematic representation of a possible morphology of the aggregates formed by SPP-P(E-Co-P) diblock copolymers in decane: bundle of polymeric rods made by crystalline/ amorphous sequences.

of the sample at room temperature aggregates resembling snowflakes have been observed. The morphology at the local scale could not be exactly resolved by using the present fully protonated copolymers. To distinguish separately the conformation of both blocks inside the aggregates will be a matter of future studies involving partially deuterated diblock copolymers.

From a comparison with the well-known morphology of the polyethylene-poly(ethylene-propylene) (PEPEP) di block aggregates in decane, ${ }^{1,3}$ we may conclude that the present propylene-containing copolymers be have differently. For PE-PEP the hairy platelet morphology was well established at the local scale: a PE crystalline core surrounded on both sides by amorphous PEP brushes. For higher $\mathrm{M}_{\mathrm{w}}$ copolymers highly extended hairy platel ets (tens of thousands of angstroms) were revealed. They assemble in stacks due to van der Waals interaction which in this case of large flat surfaces provide a significant attraction between platelets. ${ }^{1}$ The platel et stacks at a larger scale show a 1-d morphology. F or lower $M_{w}$ copolymers no stacking effect was observed, and accordingly, much smaller single platel ets have been seen. ${ }^{3}$

In the case of the SPP-P(E-co-P) copolymer the selfassembling mechanism appears to be different. The rods display diameters of many hundreds of angstroms diameter (440 and about $800 \AA$ for the low- and high$\mathrm{M}_{\mathrm{w}}$ copolymers, respectively). Thus, their inner morphology cannot be that of stacked hairy platelets because for the attractive van der Waals interaction to become effective would require much more extended platel ets. More likely, the SPP-P(E-co-P) rodlike objects are similar to the columnar supramolecular architectures formed by the rod-coil block systems (e.g., like those consisting of a molecular rod and a poly(ethylene oxide) coil ${ }^{28,29}$ ). Figure 13 displays a schematic representation of such a morphology with an inner crystalline sheetlike rod made by SPP surrounded by amorphous brushes made by PEP. This configuration agrees with the absence of any correlation peak within the intermediate and high $\mathrm{Q}$ range as in the case of platelets stack and also justifies the $\mathrm{Q}^{-2}$ behavior of the scattering patterns observed in this range because at local scale a hairy platel et-like morphology is reflected. A valida- 
tion of such a model at the first-level structure may be easily done by studying copolymers made by protonated sPP and deuterated P(E-co-P) blocks where the amorphous part will be matched with the solvent and the crystalline one is kept visible.

Concerning the self-assembling behavior reveal ed by the two SPP-P(E-Co-P) copolymers investigated here, again some questions arise: (i) What is the selfassembling mechanism behind the observed structures? (ii) What is the reason for the very different selfassembling temperatures for the copolymers with different molecular weight? (iii) Why is there no relation to the crystallization properties of pure sPP? Again the answer to these questions relates them with each other. The aggregation behavior of the two diblocks seems to be initiated by different mechanisms. The self-assembling of the higher and lower $\mathrm{M}_{\mathrm{w}}$ copolymer occurs at higher and much lower temperatures than the crystallization of SPP, respectively, and it does not follow the $\mathrm{M}_{\mathrm{w}}$ independence of the SPP homopolymers. Thus, a rationalization must refer to the effect of the $\mathrm{P}(\mathrm{E}-\mathrm{CO}-$ P) blocks.

The synthesis of the $P(E-c o-P)$ bl ock occurs by adding ethylene to the propylene solution used for building up the initial SPP segment. In this system the headgroup reactivity ratios are preferential toward ethylene. Thus, to incorporate a significant amount of propylene, reaction conditions must be adjusted, i.e., the propylene pressure. Small deviations from ideal reaction conditions as well as spatial heterogeneities in the reaction vessels could lead to the formation of prolonged ethylene units (20 or more backbone methylene carbons lead to crystallization ${ }^{30}$ ). With higher molecular weight, and consequently higher solution viscosity, the occurrence of extended ethylene sections would seem to become more likely (stirring conditions and related effects). These PE segments will cause chain aggregation at el evated temperature ${ }^{5}$ and thus give rise to an increased scattering intensity at temperatures higher than the crystallization point of SPP. Small crystallites will be formed that link together the block copolymer chains that will, in a second self-assembly step, form the aggregates discussed above. In such a case, independent of concentration, bundles of rods will be observed. This could be the case for the higher molecular weight copolymer.

On the other hand, the lower molecular weight copolymer undergoes aggregation below room temperature and provides qualitatively the same scattering patterns as the higher molecular weight self-assembled copolymer structure. This leads to the conclusion that in both cases hairy rods are formed by the selfassembling mechanism of the crystalline-amorphous diblocks. However, only in the case of the higher molecular weight sample does the self-assembly of rods in bundles occur. As noted, this could be due the presence of extended PE sequences in the $P(E-C O-P)$ block. Bundles of rods are also formed in the case of the lower molecular weight copolymer but only at higher polymer concentrations and at low temperatures.

4.3. iPP-aPP Multiblock Copolymers. Figure 14 displays the cross sections of a $0.5 \%$ dodecane solution of the aPP-iPP multiblock copolymer with a regular alternation of aPP and iPP segments at different temperatures between the single coil and aggregation regimes. The single-chain regime extends over a wide temperature range until the aggregation event starts somewhere between 110 and $85^{\circ} \mathrm{C}$. The Zimm analysis

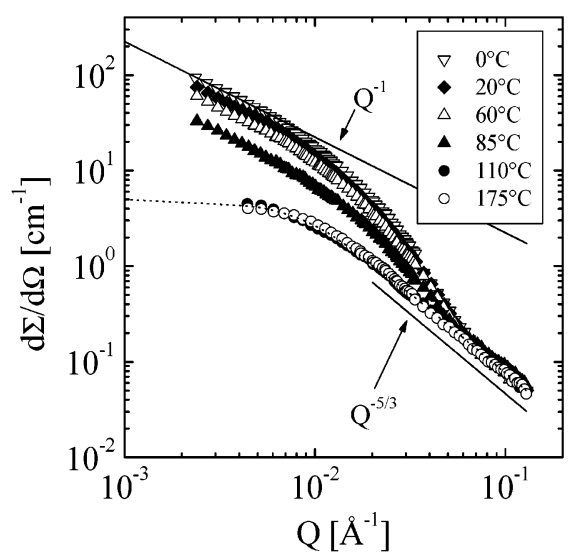

Figure 14. Scattering of iPP-aPP multiblock copolymer in dodecane: the SANS patterns at different temperatures in a log-log representation.

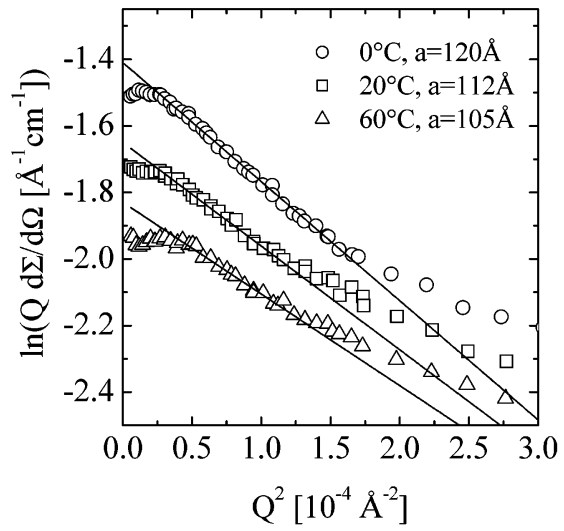

Figure 15. 1-d Guinier plot of iPP-aPP data providing the parameters of the rodlike aggregates.

provides a radius of gyration $\mathrm{R}_{\mathrm{g}}=156 \AA$ and a "forward" scattering $\mathrm{d} \Sigma / \mathrm{d} \Omega(0)=4.9 \mathrm{~cm}^{-1}$. This corresponds to a molecular weight of $107.7 \times 10^{3} \mathrm{~g} \mathrm{~mol}^{-1}$.

The scattering patterns collected at temperatures within the aggregation regime indicate a gradual selfassembling process with decreasing temperature and again a formation of 1-d objects $\left(Q^{-1}\right.$ power law behavior). At high $\mathrm{Q}$, though the polymer chains are aggregating, the intensity profile remains constant and al ways displays the same $\mathrm{Q}^{-5 / 3}$ behavior characteristic for swollen chains.

Qualitatively, the scattering results resemble those of the self-assembling of PEB-11 random ethylenebutene copolymers in decane. ${ }^{2}$ In the case of those polymers with decreasing temperature the scattering intensity is increasing at low Q, where the scattering patterns are dominated by an extended range of a $\mathrm{Q}^{-1}$ power law. At high $\mathrm{Q}$ for all temperatures, a tendency toward a $Q^{-5 / 3}$ asymptote was observed. The intensity level of this asymptote has little temperature dependence. It was concluded that though the polymers aggregate in rods these must be very open structures exhibiting singlechain structures at a local scale.

From the 1-d Guinier regime the lateral size of the rods was evaluated (1-d Guinier approximation, eq 4). Figure 15 presents the lower temperature data in such a plot. The evaluated rod radii range between $105 \AA$ at $60^{\circ} \mathrm{C}$ and $120 \AA$ at $0{ }^{\circ} \mathrm{C}$. Using the same approach as for the self-assembly of the SPP-PE/SP rods, the relation between rod volume fraction $\Phi_{\text {rod }}$ and polymer density inside rods $\Phi_{\text {pol }}^{\text {rod }}$ was quantified at $0{ }^{\circ} \mathrm{C}$. The maximum 
possible volume fraction of the polymer inside rods is $32 \%$ while the minimum is $7.2 \%$. In the latter case all polymers would be inside the rods which would occupy a maximum volume fraction of $\Phi_{\text {rod }}=8.2 \%$.

The evolution of the scattering patterns with decreasing temperature indicates a saturation of the intensity level at low $\mathrm{T}$. Therefore, at low temperature almost all polymers must be inside the aggregates. In that case, in analogy with Figure 8, the lowest polymer density inside the rods applies (7.2\%) At a local scale this leads to the typical scattering behavior of polymer coils. From these results we may conclude that the aPP-iPP multiblock copolymer in dilute hydrocarbon solution displays similar self-assembling features like the PEB-n random copolymers for which the 1-d morphology is well established.2,7 Thus, the general morphology of selfassembling materials with multiple alternating crystalline and amorphous blocks appears to be rodlike instead of 2-dimensional. The latter are favored by the crystalline-amorphous diblock architectures.

\section{Conclusion}

Information on the self-assembly and crystallization of syndiotactic poly(propylene) homopolymer and two syndiotactic poly(propylene)-poly(ethylene-propylene) diblock copolymers of different molecular weights have been obtained by SANS. While the homopolymer crystallizes by forming plates with a thickness of about $60-65 \AA$, independent of molecular weight and concentration, the diblock copolymers show a more complex behavior, yielding very large one-dimensional aggregates with radii of about 440 and $800 \AA$ for the lower and higher $M_{W}$ materials, respectively. They contain substructures and associate by forming supramolecular structures at a larger scale. The selfassembling event is highly influenced by the presence of $P E$ sequences within the $P(E-c o-P)$ block which promotes also the association in supramolecular structures like bundles and networks with sizes of tens of microns. The presently investigated diblocks display different self-assembled morphologies than the PEbased diblock copolymers where two-dimensional stacked aggregates were observed. Because only fully protonated copolymers were investigated, the conformation of blocks inside the aggregates could not be observed separately. Finally, the multiblock iPP -aPP copolymer forms onedimensional aggregates and in dilute hydrocarbon solutions reveals a very si milar self-assembling behavior as the low crystalline content PEB-n random copolymers. This demonstrates that the preferred self-assembled structure of crystalline-amorphous polymers is the 1-dimensional architecture. 2,6,7

The larger chain dimensions of the SPP-containing materials, compared to the corresponding iPP- and aPPcontaining polymers, may lend SPP, $P(E-C O-P)$, and SPP $-\mathrm{P}(\mathrm{E}-\mathrm{CO}-\mathrm{P})$ to applications as viscosity index modifiers of lubricating oils. The larger SPP chain dimensions should translate to a higher thickening efficiency than where isotactic or atactic formats predominate. Thus, for a given polymer concentration (where the molecular weights are identical) the syndiotactic material would be more effective at raising the solution viscosity than its atactic or isotactic counterparts. Also not to be overlooked is the potential for the dual function for wax crystal control in lube oils at low temperatures.
Acknowledgment. G.W.C. gratefully acknowledges a Packard F oundation Fellowship in Science and Engineering as well as funding from Mitsubishi and the Cornell Center of Materials Research (supported through the NSF MRSEC program, DMR-0079992). L.J .F. thanks Cornell University for the Mary K. Upson visiting professorship. We acknowledge the assistance of $\mathrm{Dr}$. J . Stell brink and Dr. E. Kentzinger at the KWSIII instrument.

\section{References and Notes}

(1) Richter, D.; Schneiders, D.; Monkenbusch, M.; Willner, L.; Fetters, L. J .; Huang, J. S.; Lin, M.; Mortensen, K.; Farago, B. Macromolecules 1997, 30, 1053-1069.

(2) Schwahn, D.; Richter, D.; Wright, P. M.; Symon, C.; Fetters, L. J .; Lin, M. Macromolecules 2002, 35, 861-870.

(3) Leube, W.; Monkenbusch, M.; Schneiders, D.; Richter, D.; Willner, L.; Adamson, D. H.; Fetters, L. J .; Dounis, P.; Lovegrove, R. Energy Fuels 2000, 14, 419-430.

(4) Schwahn, D.; Richter, D.; Fetters, L. J .; Lin, M. Macromolecules 2002, 35, 3762-3768.

(5) Ashbaugh, H. S.; Fetters, L. J .; Adamson D. H.; Prud'homme, R. K. J. Rheol. 2002, 46, 763-776.

(6) Ashbaugh, H. S.; Radulescu, A.; Prud'homme, R. K.; Schwahn, D.; Richter, D.; Fetters, L. J. Macromolecules 2002, 35, 7044-7053.

(7) Radulescu, A.; Schwahn, D.; Monkenbusch, M.; Fetters, L. J .; Richter, D. J . Polym. Sci., Part B: Polym. Phys., in press.

(8) Tian, J.; Hustad, P. D.; Coates, G. W. J . Am. Chem. Soc. 2001 123, 5134-5135.

(9) Coates, G. W.; Waymouth, R. M. Science 1995, 267, 217-219.

(10) Rodriguez-Arnold, J .; Bu, Z.; Cheng, S. Z. D.; Hsieh, E. T.; J ohnson, T. W.; Geerts, R. G.; Palackal, S. J .; Hawley; G. R.; Bruce Welch, M. Polymer 1994, 35, 5194-5201.

(11) Schwahn, D.; Hahn, K.; Streib, J .; Springer, T.J . Chem. Phys. 1990, 93, 8383-8391.

(12) See: http://www.fz-juelich.de/iff/wns_kws3/.

(13) Higgins, J. S.; Benoit, H. Polymers and Neutron Scattering; Clarendon Press: Oxford, 1994.

(14) Beaucage, G.; Schaefer, D. W. J . Non-Cryst. Solids 1994 172-174, 797-805.

(15) Ramzi, A.; Prager, M.; Richter, D.; Efstratiadis, V.; Hadjichristidis, N.; Y oung, R. N.; Allgaier, J . Macromol ecules 1997, 30, 7171-7182.

(16) J ones, T. D.; Chaffin, K. A.; Bates, F. S.; Annis, B. K.; Hagaman, E. W.; Kim, M. H.; Wignall, G. D.; Fan, W.; Waymouth, R. Macromolecules 2002, 35, 5061-5068.

(17) Marchetti, A.; Martuscelli, E. J . Polym. Sci., Polym. Phys. Ed. 1974, 12, 1649-1666.

(18) Boor, J .; Youngman, E. A. J . Polym. Sci., Part A-1 1966, 4 1861-1884.

(19) Lotz, B.; Lovinger, A. J .; Cais, R. E. Macromolecules 1988, $21,2375-2382$.

(20) Lovinger, A. J .; Lotz, B.; Davis, D. D.; Padden, F. J ., J r. Macromolecules 1993, 26, 3494-3503.

(21) Lovinger, A. J .; Lotz, B.; Davis, D. D.; Schumacher, M. Macromol ecules 1994, 27, 6603-6611.

(22) Lacks, D. J .; Rutledge, G. C. Macromolecules 1995, 28, 57895792.

(23) Mortensen, K.; Pedersen, J. S. Macromolecules 1993, 26, 805-812.

(24) Mortensen, K. J . Phys.: Condens. Matter 1996, 8, A103-A124.

(25) Hoffmann, H.; Kalus, J.; Schwander, B. Ber. Bunsen-Ges. Phys. Chem. 1987, 91, 99-106.

(26) Maier, E. E.; Schultz S. F.; Weber, R. Macromolecules 1988, $21,1544-1546$

(27) Canessa, E.; D’Aguanno, B.; Weyerich, B.; Klein, R. Mol. Phys. 1991, 73, 175-197.

(28) Lee, M.; Cho, B.-K.; Kim, H.; Yoon, J .-Y.; Zin, W.-C. J . Am. Chem. Soc. 1998, 120, 9168-9179.

(29) Lee, M.; Lee, D.-W.; Cho, B.-K. J . Am. Chem. Soc. 1998, 120, $13258-13259$

(30) Davison, S.; Taylor, G. Br. Polym. J . 1972, 4, 65-70. MA049426E 